\title{
Enurese na adolescência: estudo de caso com intervenção comportamental
}

\author{
Noel José Dias da Costa \\ Edwiges Ferreira de Mattos Silvares \\ Universidade de São Paulo
}

\begin{abstract}
Resumo
Um relato de caso de tratamento em terapia cognitivo-comportamental de dois adolescentes que apresentavam enurese noturna é descrito. Um padrão usual de intervenção clínica cognitivocomportamental foi empregado tendo o aparelho de alarme de urina brasileiro como adjunto terapêutico. Primeiro, uma avaliação comportamental foi desenvolvida através de entrevista com o adolescente e com os familiares, aplicação de inventários e automonitoria das molhadas noturnas para construção de uma linha de base do controle urinário. Depois, foram processadas sessões individuais com os adolescentes e seus familiares. As sessões terapêuticas foram semanais, para o participante e seus pais, separadamente. Os questionários aplicados ao início e final do trabalho foram: o CBCL (Child Behavior Checklist, Achenbach, 1991), a Escala de Intolerância (Morgan \& Young, 1975), o Formulário de Avaliação de Enurese (Blackwell, 1989), a Entrevista Semi-Estruturada de Butler (1987). O registro de frequiência de molhadas foi obtido durante todo o tratamento. Utilizou-se o treino familiar em resolução de problemas, do modelo triádico de atendimento comportamental, considerando-se diversas variáveis cognitivas além das dificuldades específicas do adolescente. A freqüência inicial de "molhadas à noite" caiu de 3-4 vezes por semana para zero, ao cabo de oito semanas. O critério de alta de oito semanas consecutivas sem molhadas noturnas foi alcançado para os dois adolescentes. Os resultados indicam a utilidade desta metodologia como um potente instrumento para atender adolescentes com essa queixa.
\end{abstract}

Palavras-chave: aparelho de alarme; enurese; adolescência.

\begin{abstract}
Enuresis in adolescence: behavioral intervention case study

This describes a case study report on cognitive-behavioral therapy of two adolescents with nocturnal enuresis. The treatment followed the usual pattern of cognitive- behavioral intervention, using a Brazilian designed urine alarm device as a therapeutic adjunct. Firstly a behavioral assessment was conducted of interviews with the adolescent and with his/her parents, application of inventories and self-monitoring of wet nights in order to define a urine control baseline. Secondly, therapeutic sessions on cognitive behavioral orientation were developed individually and on a weekly basis, for both participants (adolescent and his parents, separately interviewed). The applied questionnaires at the beginning and at the end of the study were the CBCL (Child Behavior Checklist, Achenbach, 1991), the Scale of Intolerance (Morgan \& Young, 1975), the Blackwell (1989) Form to evaluate enuresis (Blackwell, 1989), and Semi-Structured Interview of Butler (1987). Self monitory of wet nights was followed during treatment. Parent training on resolution of the problem was selected as a model for cognitive-behavioral intervention and several cognitive variables besides the adolescent's specific difficulties were focused upon. The frequency of wet nights fell from 3 to 4 per week to zero, after eight weeks. The criterion of eight consecutive weeks without wet nights was reached by both adolescents. The results show the usefulness of this methodology as a powerful instrument to help adolescents with this particular problem.
\end{abstract}

Keywords: urine alarm device; enuresis; adolescence.

A enurese é considerada como um ato de micção repetida e inadequada (Souza, Oliveira \& Von Poser, 1995) e se refere ao urinar acidental ou incontrolado (Mellon \& Houts, 1995) sendo definida funcionalmente como "o molhar-se que ocorre na ausência de patologia urológica ou neurológica" (Doleys, 1977). É enquadrada pela psicopatologia atual como uma desordem funcional de eliminação que requer tratamentos médico-psicológicos (Mellon $\&$ Houts, 1995).

O DSM-IV estabelece quatro critérios para diagnóstico da enurese: a) micção repetida, diurna ou noturna, na cama ou na roupa; b) a micção deve ocorrer no mínimo duas vezes por semana por pelo menos três meses, ou então causar um sofrimento ou prejuízo significativo no funcionamento social, 
acadêmico (ocupacional) ou outras áreas importantes na vida do indivíduo; c) é esperado que a continência ocorra com a idade cronológica de no mínimo cinco anos: d) a incontinência urinária não se deve exclusivamente aos efeitos fisiológicos diretos de uma substância (por exemplo, diuréticos) ou a uma condição geral (por exemplo, diabete, espinha bífida, transtorno convulsivo) (American Psychiatric Association, 1994).

Este distúrbio, portanto, se evidencia pela falta do controle vesical (continência urinária) em uma idade em que já se deveria tê-lo. Apesar de subordinado a processos neurofisiológicos de amadurecimento, existem variações culturais relacionadas à idade ideal para aquisição do mesmo - geralmente entre 3 e 5 anos na cultura ocidental (Oliveira, 1999).

\section{Tipos}

A enurese pode ser classificada pelo momento em que ela ocorre na vida da criança e o momento do dia no qual ocorrem os episódios de "molhadas" (episódios enuréticos). Tomando-se o primeiro critério, pode ser primária (contínua, persistente ou crônica) - no caso de a criança nunca ter apresentado o controle vesical - ou secundária (descontínua, "onset", regressiva ou adquirida) - no caso de a continência já ter sido verificada na criança por um período de pelo menos seis meses (Doleys, 1977).

Quanto ao momento do dia dos episódios, ela tem sido classificada em diurna ou em vigília (ocorrendo durante o dia, quando a criança está ou deveria estar acordada) e noturna ou durante o sono (ocorrendo à noite, enquanto a criança dorme ou deveria estar dormindo).

\section{Epidemiologia}

Butler, Holland e Robinson (2001) afirmam que a enurese noturna é marcadamente prevalente em crianças, afetando 9-13\% das crianças de nove anos e $1-2 \%$ dos adolescentes e adultos jovens. Segundo estes autores, as crianças afetadas por esta condição podem se tornar isoladas socialmente, com problemas emocionais e baixa auto-estima. Uma melhora, complementam os autores, no funcionamento psicológico, incluindo a auto-estima, tem sido reportada depois de tratamentos bem sucedidos. Butler (2001) relata que, apesar de a maioria dos pais serem suportivos, há um número significante, acima de $30 \%$, que se tornam intolerantes à enurese noturna de seus filhos. Então, a enurese pode ter um efeito marcado sobre a dinâmica familiar e as formas de tratamento para esta condição não podem ser ignoradas.

As estatísticas norte-americanas apontam 5 milhões de crianças sofrendo de enurese noturna (Houts, 1991). A enurese é um problema comum entre crianças de idade pré-escolar, envolvendo $7 \%$ dos meninos e 3\% das meninas (Oliveira, 1999).

\section{Etiologia}

A enurese noturna caracteriza-se por uma interação altamente complexa entre fatores orgânicos e psíquicos. A despeito do sono profundo, onde há dificuldade de acordar, a arquitetura do sono em si mesma é normal, e episódios enuréticos ocorrem em todos os estágios do sono. Mudanças no ritmo circadiano com enurese noturna têm sido muito relatadas. Estudos também têm demonstrado uma ligação entre a enurese noturna e regiões dos cromossomos n. 8, 12 e 13. As associações são complexas, com fatores psicológicos ocorrendo junto com a enurese, bem como envolvidos com a etiologia da enurese secundária (Gontard, Alexander \& Lehmkuhl, 1997).

Djurhuus e Rittig (2002), em revisão da literatura, afirmam que um dos fatores etiológicos da enurese noturna é a deficiência na secreção da vasopressina mas que outros mecanismos etiológicos atuam concomitantemente no organismo. $\mathrm{O}$ estudo da capacidade de armazenamento da bexiga tem ganho notoriedade pois este fator tem provado ser um dos maiores preditores da resposta ao tratamento. Vários aspectos do sistema nervoso central, incluindo capacidade de excitação e reflexos, estão em foco, e a genética molecular tem trazido firmes evidências da relação entre a enurese e diferentes marcadores cromossômicos.

Ainda segundo Djurhuus e Rittig (2002), a despeito dos avanços recentes em nosso entendimento sobre enurese noturna, nós ainda estamos muito longe da completa compreensão desta condição cientificamente intrigante e socialmente desconfortante. Felizmente, contudo, o fato de a enurese ser uma condição heterogênea, que requer pesquisas diferenciadas, tem servido como embasamento para progressos posteriores.

\section{Enurese e adolescência}

Enquanto o problema da enurese não é resolvido, outros problemas comportamentais vão se ampliando (discriminação social, impedimento de realizar atividades, como dormir na casa de amigos, viajar em excursões escolares etc.). Se a criança e sua família sofrem, recebendo impacto negativo sobre sua autoestima (Silvares, 1996), o que dizer então do adolescente, que nesse período evolutivo tem nos pares o seu grupo de referência? Este, por ter maior discernimento que as crianças, sofre ainda mais, uma vez que as limitações impostas pela enurese implicam a impossibilidade da participação em algumas atividades sociais, além de obrigá-lo a manter o "segredo" pelo receio de rejeição do grupo (Aberastury \& Knobel, 1992). Para eles, portanto, o tratamento é imperioso.

\section{A Relação Familiar e a Enurese}

$\mathrm{O}$ ato de urinar na cama pode se tornar um fator desencadeante de problemas emocionais para $o$ adolescente, tais como ansiedade, vergonha, tristeza, desânimo e auto-estima baixa. Os pais também podem sentir vergonha, angústia e ansiedade diante de um fato que não conseguem explicar:

As queixas em torno da enurese costumam ser a dificuldade que os pais enfrentam em acordar à noite numa tentativa de prevenir que a criança molhe a cama, e o desconforto das crianças que, ao urinarem na cama, acabam dormindo em colchões molhados e com cheiro de urina (Oliveira, 1999). 
Dentre outros, esses aspectos tornam imperiosa a participação dos mediadores (pais ou responsáveis) no processo. As perdas experimentadas pelo adolescente que se vê limitado em seus relacionamentos, impedido de fazer passeios em que tenha de dormir fora de sua casa; a auto-imagem associada a um estigma e a sensação de impotência frente à superação de uma dificuldade já vencida pelos seus pares, todos esses aspectos, dentre outros, tornam imperativo o envolvimento dos pais no processo. Essa participação implica atitudes de acolhimento, compreensão e cooperação para com o adolescente que necessita de reforçadores para boa adesão ao tratamento.

Por isso, utilizou-se o modelo triádico de atendimento comportamental. Segundo Silvares (1998), esse modelo possibilita a utilização de tipos de intervenção possíveis e desejáveis para as especificidades das diferentes famílias-clientes. Duas formas bastante conhecidas desde a implantação do modelo são: a) Treino de pais em manejo de contingências (Hawkins, Peterson, Shweid e Bijou, 1966) e b) Contrato de Contingências (Miller \& Kelley, 1994). Nestes dois tipos são consideradas apenas as variáveis: comportamentos inadequados e as conseqüências ambientais sobre eles. Pela necessidade de se considerar outras variáveis, além das dificuldades específicas da criança (como por exemplo: conflitos conjugais), surgiu outra modalidade: c) Treino Familiar em Resolução de Problemas.

A necessidade da participação dos pais e da família no tratamento tem um papel importante na diminuição da ansiedade potencializada pelas adversidades familiares, como apresentam Laberg e cols. (2000) através de estudo comparativo com sujeitos de 3 a 13 anos de idade aplicando-lhes escalas que mensurariam o nível de ansiedade e o índice de adversidade familiar. Os autores consideraram a enurese noturna como uma parassonia e não acharam correlação entre a enurese e a ocorrência de outras parassonias. O nível de prevalência achado aos 13 anos $(2 \%)$ é similar à prevalência de $1,5 \%$ a $3 \%$ achado na população adulta. Os resultados também confirmaram uma maioria de enuréticos do sexo masculino. O estudo achou relação entre todas as parassonias estudadas, inclusive a enurese, e altos índices de adversidade familiar em crianças e adolescentes até 11 anos.

\section{Tratamento}

Entre as técnicas de tratamento para enurese existem as de terapia comportamental, tais como treinamento de retenção e o treinamento de contenção; sendo o primeiro o processo pelo qual, ao urinar-se, retem-se a urina após o primeiro jato por um período de tempo crescente a cada nova micção. $O$ segundo, consiste em reter-se a urina por um período de tempo cada vez que se manifeste o desejo de urinar. Este período de tempo, como no treinamento de retenção, deve ser crescente a cada nova micção. Há também o uso de agentes farmacológicos: antidepressivos tricíclicos, desmopressina e anticolinérgicos. Além disto, a terapia alimentar, na qual evitam-se alimentos diuréticos, e combinações de terapia do condicionamento e desmopressina são usadas para o tratamento de enurese noturna (Moffat, 1997).

Van Kampen (2002) sugere que a terapia de amplo espectro, envolvendo aparelho de alarme para urina, treino de retenção de urina e terapia motivacional, é o tratamento mais eficaz, independente de idade, gênero, capacidade da bexiga e história familiar do cliente.

\section{Aparelho de Alarme}

Wille (1986) comparou o tratamento feito com aparelho de alarme para enurese com a administração de desmopressina. Seus achados mostram que a maior freqüência de declínio na taxa de enurese foi entre o grupo que utilizou o aparelho de alarme. Ao longo do tratamento, $42 \%$ das crianças que receberam desmopressina e $82 \%$ das crianças que foram tratadas com aparelho de alarme diminuíram o número de noites em que acordavam molhadas. Em ambos os grupos a taxa de cura foi maior do que a taxa de cura espontânea, que é de $15 \%$. O autor encerra seu texto dizendo acreditar que o alarme de enurese é a primeira escolha de tratamento, mas quando não for possível o acesso a ele, o tratamento alternativo é a desmopressina.

Pesquisas recentes sobre a etiologia e patofisiologia do problema oferecem promissoras pistas para o entendimento de como os tratamentos com o alarme-urina produzem efeitos positivos e superiores aos demais métodos atualmente disponíveis. Os resultados parecem indicar efetiva liberação noturna de $\mathrm{ADH}$ endógeno e a regulação das respostas musculares que envolvem o "molhar a cama".

Houts (1991) aponta para a possibilidade de o aparelho atuar no aumento da liberação de vasopressina, o hormônio antidiurético (ADH). O autor afirma que aumentos no nível plasmático de vasopressina correspondem a uma parte da resposta fisiológica ao stress. Ser acordado no meio da noite, durante o urinar, pode aumentar a produção de $\mathrm{ADH}$ endógeno.

Outro mecanismo de ação do aparelho pode envolver o condicionamento das respostas da musculatura da bexiga ao preenchimento desta com urina, possibilitando a retenção de urina através da estabilização do músculo da bexiga (Houts, 1991). Este último mecanismo de ação pode explicar o fato de que, em nossa experiência clínica, crianças treinadas com o aparelho, ao receberem alta, não acordam no meio da noite para urinar, como se aumentassem sua capacidade de retenção de urina na bexiga. Por outro lado, crianças tratadas sem o aparelho, ao receberem alta, acordam no meio da noite para urinar no banheiro.

Tratamentos psicológicos são geralmente mais efetivos do que os tratamentos farmacológicos. Em particular, o tratamento psicológico aliado ao aparelho de alarme para enurese é superior a qualquer outro tipo de intervenção. O follow-up de crianças tratadas com o aparelho de alarme foi quase duas vezes melhor sucedido do que o das crianças que receberam outros tratamentos. Além disto, informações recentes sobre 
os efeitos cardiotóxicos em potencial da intoxicação por imipramina trazem sérios questionamentos sobre o uso indiscriminado da imipramina no tratamento de enurese (Houts e cols., 1994).

Descreveremos a seguir os procedimentos empregados no tratamento de dois adolescentes enuréticos, atendidos na clínica psicológica do Instituto de Psicologia da Universidade de São Paulo. $\mathrm{O}$ primeiro adolescente, de 15 anos de idade, do sexo masculino, será aqui identificado como L. e o segundo, do sexo feminino, de 14 anos, será identificado como $\mathrm{J}$.

Foram utilizados os seguintes instrumentos de avaliação: a) CBCL (Inventário do Comportamento Infantil, Achenbach, 1991), através do qual coletamos informações sobre a percepção dos pais acerca de seus filhos antes e após a intervenção; b) YRF (Questionário de Auto-Avaliação para Jovens, Achenbach, 1991), através do qual coletamos informações sobre a percepção dos adolescentes sobre si mesmos antes e após a intervenção; c) Escala de Intolerância à Enurese de Morgan e Young (1975), através do qual aferimos o nível de tolerância ou rejeição dos pais a cerca da enurese dos filhos; d) Formulário de Avaliação de Enurese, de Blackwell (1989), que delimita se a enurese é noturna ou diurna, primária ou secundária, múltipla ou não, sua freqüência etc; e) Entrevista semi-estruturada de Butler (1987), que retrata a percepção do indivíduo a respeito de sua enurese e do comportamento dos outros (família e colegas) com relação a ela.

Em ambos os casos, o tratamento se deu através de atendimento individual, com uma sessão semanal para o adolescente e uma sessão para seus pais. Foi utilizado como recurso auxiliar um aparelho de alarme de urina de fabricação nacional, de tecnologia inglesa, desenvolvido em parceria com a Escola Politécnica da Universidade de São Paulo. Ele é composto de uma unidade sensora, que é um circuito impresso em poliéster, na forma de um pequeno "tapete" (para ser colocado sobre o colchão e sob o lençol) e uma unidade de alarme; ambas ligadas por um cabo. Quando a urina molha o tapete, o alarme é acionado.

As instruções quanto ao procedimento no uso do aparelho resumem-se no seguinte: a) durante o período do tratamento, o participante deve abster-se de líquidos até duas horas antes de deitar-se; b) deve também evitar uso de refrigerantes, chá, café e chocolate à noite; c) antes de deitar, deve providenciar outro lençol e outra roupa para se trocar, em caso de episódio de molhada; d) deve ligar o aparelho ao deitar-se; e) no caso de o aparelho tocar o alarme, deve desligá-lo e em seguida ir ao banheiro para terminar a micção;f) depois, deve trocar de roupa, e também de lençol; g) em seguida deve ligar o aparelho e deitar-se; h) em todas as manhãs deve fazer registro indicando se houve ou não episódio de molhadas, bem como as observações referentes a outros eventos relacionados a esse comportamento, caso ocorram (por exemplo: eventos estressantes; o acordar espontâneo durante a noite; episódios múltiplos etc).

\section{RELATO DE CASO}

\section{Primeiro cliente}

O cliente L. esteve sob cuidados médicos durante dois anos, antes de passar pela psicoterapia, sem contudo obter sucesso no controle vesical. Apresentava enurese noturna primária com frequiência semanal de 5 molhadas. Os episódios ocorriam também quando ele dormia de dia. Os pais já haviam recorrido a estratégias de recompensa e punição, método de despertar o filho à noite e supressão de líquidos à noite. Nenhum desses métodos resultou em ganhos para o seu comportamento.

A história de vida de L. parece mostrar como esse comportamento se instalara e como se mantinha. Terceiro filho de uma família de seis irmãos, era tímido. Seus pais trabalhavam, ficando seu cuidado a cargo da avó. Os irmãos mais velhos possuíam mais habilidades nas interações sociais. Eram-lhes confiadas responsabilidades e desfrutavam algumas vantagens como liberdade para brincar com colegas vizinhos. Ao contrário deles, L. não conseguia manter interações com seus pares.

Ao perceberem sua falta de controle vesical, os pais tentaram superá-la a princípio através de constantes punições, a começar com a exigência de que ele mesmo lavasse suas roupas de cama até privação de atividades de lazer, confirmando assim a baixa tolerância deles para com o problema. Quando ele atingiu os treze anos, a mãe, não suportando mais o problema, decidiu ameaçá-lo. Com receio da punição, ele passou a tentar não dormir à noite para poder ir ao banheiro no momento em que a bexiga estivesse cheia. Durante o dia, porém, quando sentia sono tentava obstruir a micção através do uso de pregador de roupa. Como consequiência teve lesões e dores que exigiram cuidados médicos.

Esse episódio, entretanto, levou a mãe a procurar a clínica de psicologia. Inicialmente ele demonstrou-se muito reservado. Utilizamos, então, recursos lúdicos para superar essa barreira. Através de jogos ele conseguiu adaptar-se melhor. As sessões subseqüentes foram mais produtivas.

Nas sessões com o cliente, buscou-se avaliar e tratar suas tensões e expectativas quanto à queixa. Inicialmente o conteúdo de sua fala apresentava temas periféricos, contudo, ao final emergiam temas ligados às suas dificuldades de interação e problemas familiares, decorrentes de seu problema. Através dos registros diários, feitos por ele, foi possível perceber a relação existente entre aumento da frequiência do comportamento enurético com eventos estressantes. Buscou-se, então, focar a administração desses eventos, bem como a superação dos mesmos. Nas sessões com os pais, após uma análise funcional inicial, buscou-se abordar questões ligadas às trocas afetivas, que diziam respeito à queixa. A princípio apenas sua mãe comparecia à clínica. Depois, o pai também começou a participar das sessões. Ele manifestou as dificuldades de interação com o filho, o que se tornou objeto de algumas sessões, dentre outros temas. Os dados do CBCL de ambos assinalavam para 
uma percepção bem focal quanto à queixa de enurese de seu filho, pois ambos tiveram escores baixos, inferiores a 60, assim, viam seu filho como não clínico, ou seja, para eles, a queixa de enurese era um problema isolado, que não implicava que seu filho tivesse dificuldades globais.
Ao longo do processo, os pais modificaram sua interação com o cliente, principalmente nas questões ligadas à sua queixa, através de atitudes de compreensão, tolerância, cooperação e acolhimento. Eles também não mais reforçaram o comportamento enurético pela excessiva atenção nos dias em que ele se manifestava.

Fig. 1: Escores de distúrbio total, distúrbio internalizante e distúrbio externalizante obtidos no CBCL dos pais de L.

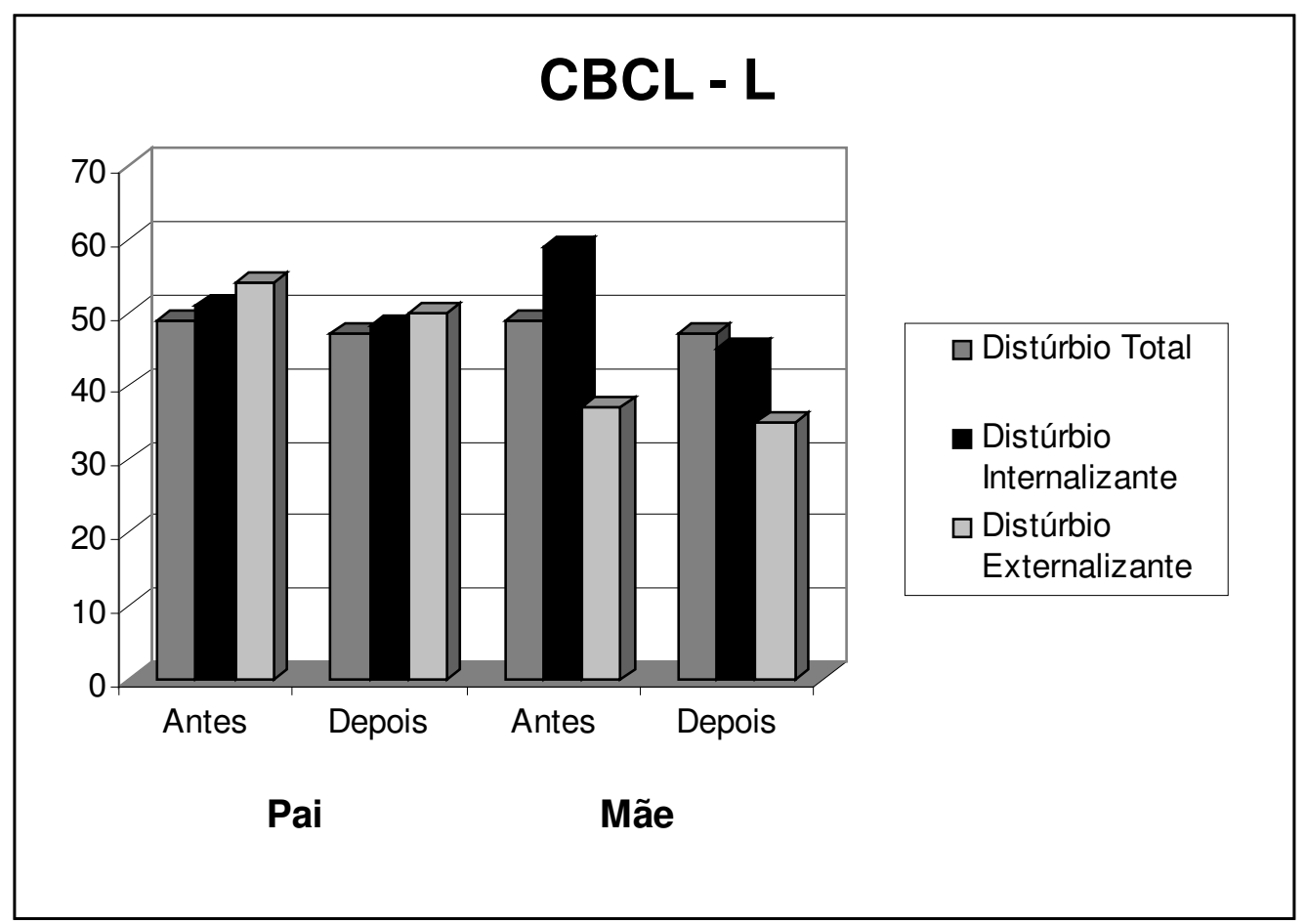

Após cinco semanas de tratamento, foi introduzido o aparelho de alarme como auxiliar no tratamento. $\mathrm{O}$ cliente e seus pais receberam instruções sobre o uso e cuidados com o aparelho (conforme descrito anteriormente) bem como seus possíveis desconfortos. Após a terceira semana de uso não ocorreram mais molhadas por sete semanas consecutivas. Após estas houve apenas uma ocorrência na semana subseqüente, reiniciando-se um ciclo de 13 semanas sem uma molhada sequer.

O critério para o término do tratamento tem sido de oito semanas consecutivas sem ocorrência de molhadas. Contudo, optou-se por um período de tempo maior para que se efetuasse a superaprendizagem, que consiste num método que visa reduzir a possibilidade de recaídas ao se usar o aparelho de alarme. Ao se analisar os mecanismos fisiológicos envolvidos no controle urinário, é possível identificar o processo denominado superaprendizagem no fato de que os músculos detrussores da bexiga são tensionados adicionalmente através da ingestão de líquido extra. $\mathrm{Na}$ medida em que isso é tolerado, o controle da bexiga é progressivamente fortalecido. Nesse processo, o uso do aparelho de alarme deve prosseguir normalmente, mas deve ser fornecida à criança - uma hora antes de ela se deitar - uma quantidade maior de líquido que ela possa confortavelmente beber (comumente, iniciando de meio até se chegar a um copo e meio).

Ao término do atendimento pode-se verificar seus efeitos positivos na extinção do comportamento enurético, como também em outros aspectos da vida do cliente. Além de haver ampliado seu campo social, também tomara iniciativas até então não percebidas em seu repertório, como interagir com garotas e até mesmo namorar. Também conseguiu inserir-se em grupos artísticos com atividades regulares.

Fig. 2: Freqüência semanal de episódios de molhadas (acidentes enuréticos) do Adolescente $L$ antes e durante a intervenção. 


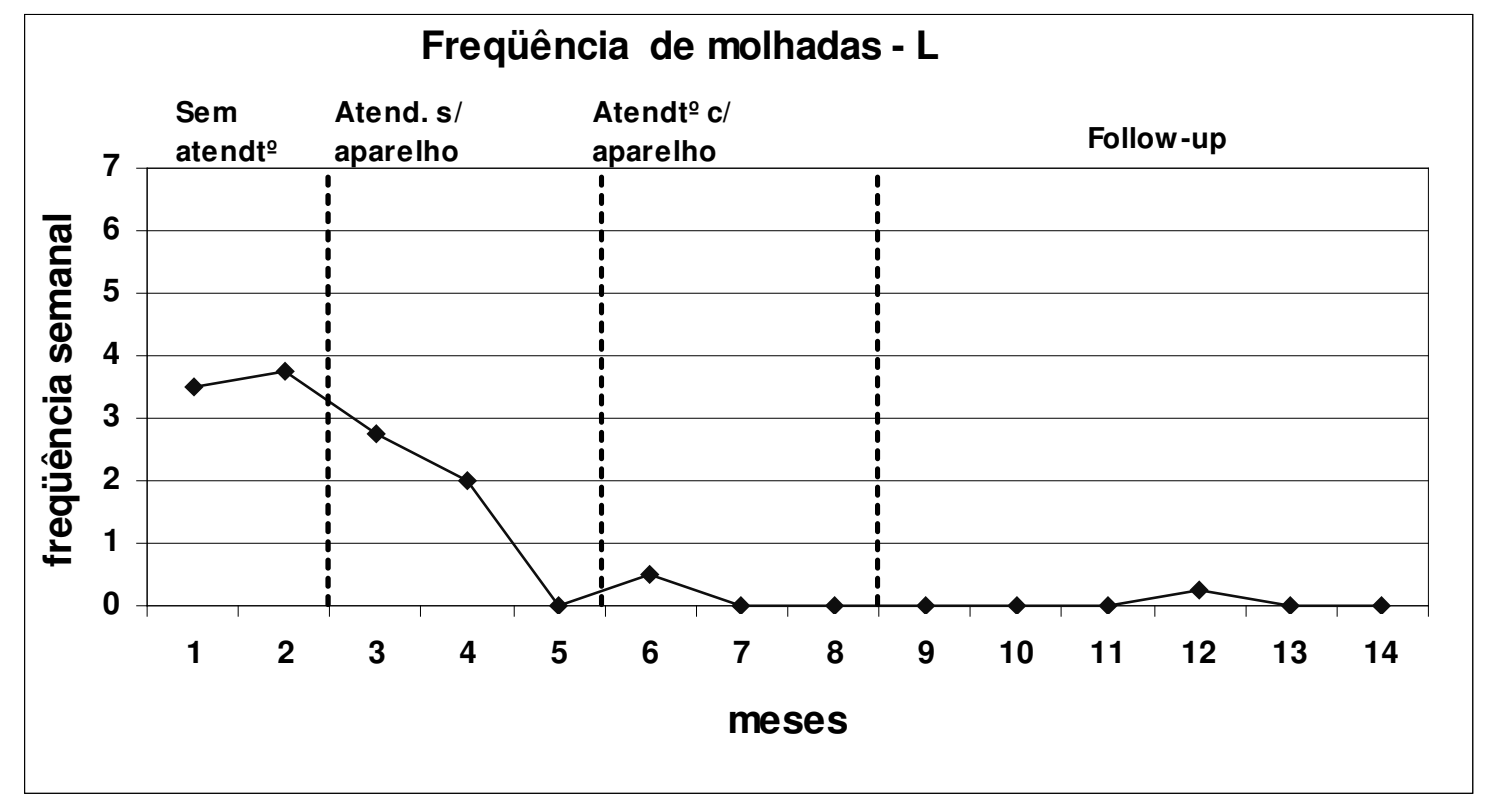

Os resultados sinalizaram melhora na dinâmica familiar, pois, ao compreenderem os pais, o fenômeno da enurese, seus fatores e estratégias de controle, tiveram suas tensões diminuídas e maior tolerância quanto ao mesmo. As trocas afetivas foram modificadas, de afetos negativos sempre presentes nos dias em ocorriam as molhadas, para afetos positivos na forma de reforços sociais nos dias em que elas não ocorriam. Isto ocasionou uma interação mais positiva e integrada da família.

Dados fornecidos por telefone, no seguimento de seis meses, sinalizam para a superação da queixa e manutenção de novos comportamentos adquiridos no atendimento.

\section{Segundo cliente}

A adolescente J., 14 anos de idade, é a segunda filha de um casal com quatro filhos, sendo o mais velho do sexo masculino e as duas mais novas do sexo feminino, e gêmeas.

Segundo relato dos pais, ao completar três anos de idade, J. adquiriu a continência urinária. Aos quatro anos, entretanto, nasceram suas irmãs, e reiniciaram- se os episódios de molhadas. Os pais imaginavam que passariam logo, o que não aconteceu. Aos sete anos de idade, procuraram tratamento médico, sem obter êxito. Foram orientados a aguardarem por uma melhora espontânea, resultante do desenvolvimento maturacional, o que também não ocorreu. Ao longo desse processo, procuraram algumas soluções domésticas, como recompensa e punições e abstenção de líquido à noite. Depois de tentarem vários métodos, solicitaram atendimento na clínica psicológica do IPUSP, ocasião em que se verificou ser a taxa de frequiência de molhadas de 4 por semana.

Os pais pareciam ter tolerância em relação ao problema. Entretanto, os dados do CBCL (Achenbach, 1991) indicaram que o pai a percebia como limítrofe no quesito distúrbio total, e como clínica, no item distúrbios internalizantes (Fig. 3). O atendimento possibilitou sua compreensão do manejo de contingências e de seu papel na alteração das mesmas, bem como outros aspectos relativos à queixa. As interações foram alteradas possibilitando diálogo e abertura para exposição de sentimentos e pontos de vista.

Fig. 3: Escores de distúrbio total, distúrbio internalizante e distúrbio externalizante obtido no CBCL dos pais de J. 


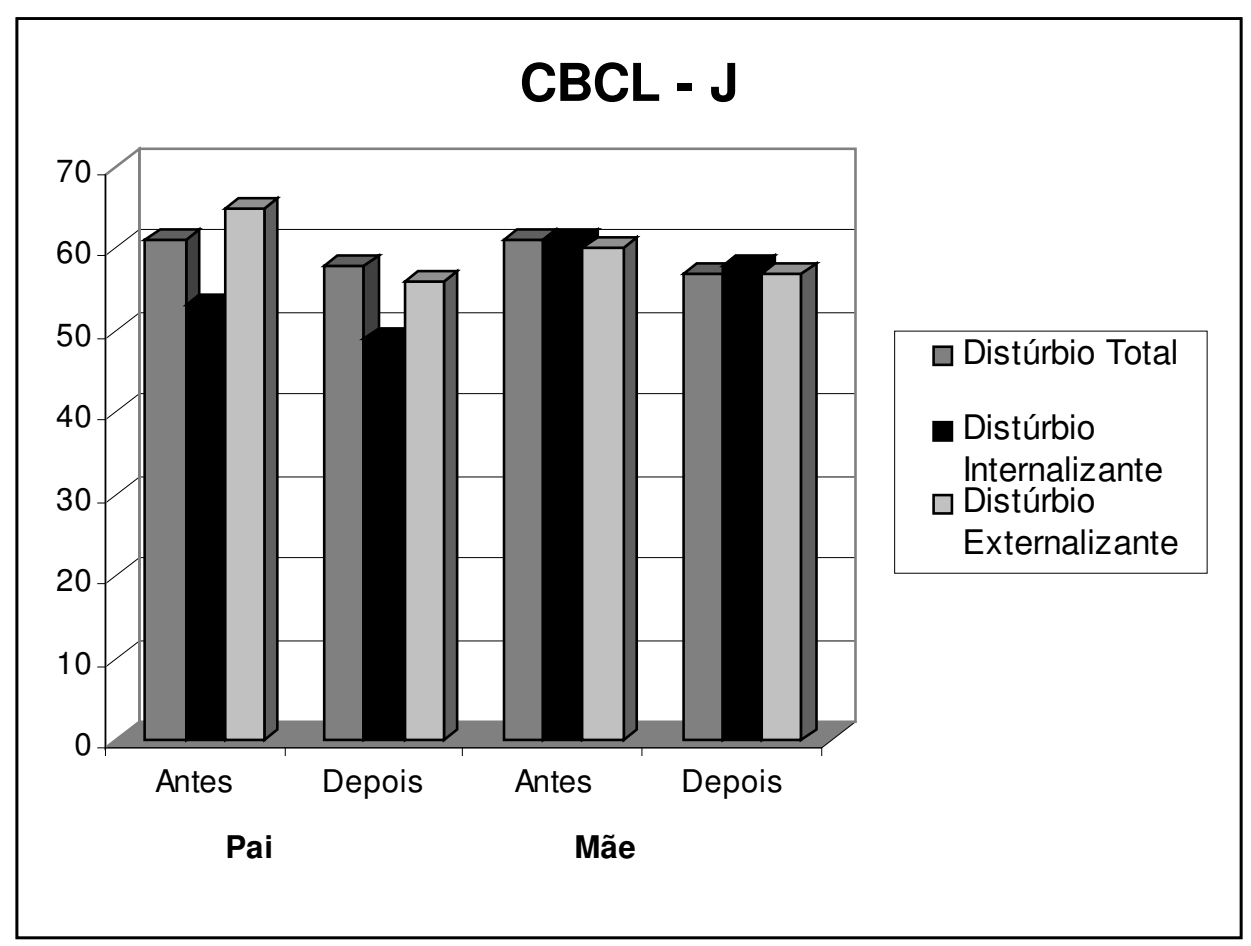

Nas sessões iniciais J. apresentava com freqüência questões ligadas à sua rivalidade com as irmãs, sem afirmar tal fato. Geralmente, seus relatos diziam respeito aos supostos privilégios delas em detrimento de seus esforços e sacrifícios para auxiliá-las e para manter a casa em ordem, enquanto os pais e o irmão mais velho trabalhavam. Sua adequada adaptação ante esses incidentes ocupou considerável espaço nas primeiras sessões. Outros temas foram também abordados, tais como: sua timidez e dificuldade em fazer novos relacionamentos; sua baixa tolerância a críticas, principalmente das irmãs; seu medo de perder os relacionamentos já estabelecidos. $\mathrm{Na}$ percepção dela, pelos seus relatos e registros diários, e também pelos relatos de seus pais, quando eventos dessa natureza ocorriam, as molhadas noturnas se manifestavam.

Essas questões foram abordadas, levando-se em conta, principalmente, suas semelhanças e associação ao comportamento ansioso, de insegurança e irritabilidade, e relação com a freqüência das molhadas noturnas. Procurou-se desenvolver sua percepção dos possíveis determinantes e das melhores estratégias de enfrentamento.

A evolução do caso apresentado em termo da diminuição dos episódios de molhadas é demonstrada quantitativamente através da Fig. 4.

Fig. 4: Freqüência semanal de episódios de molhadas (acidentes enuréticos) da Adolescente J antes e durante a intervenção. 


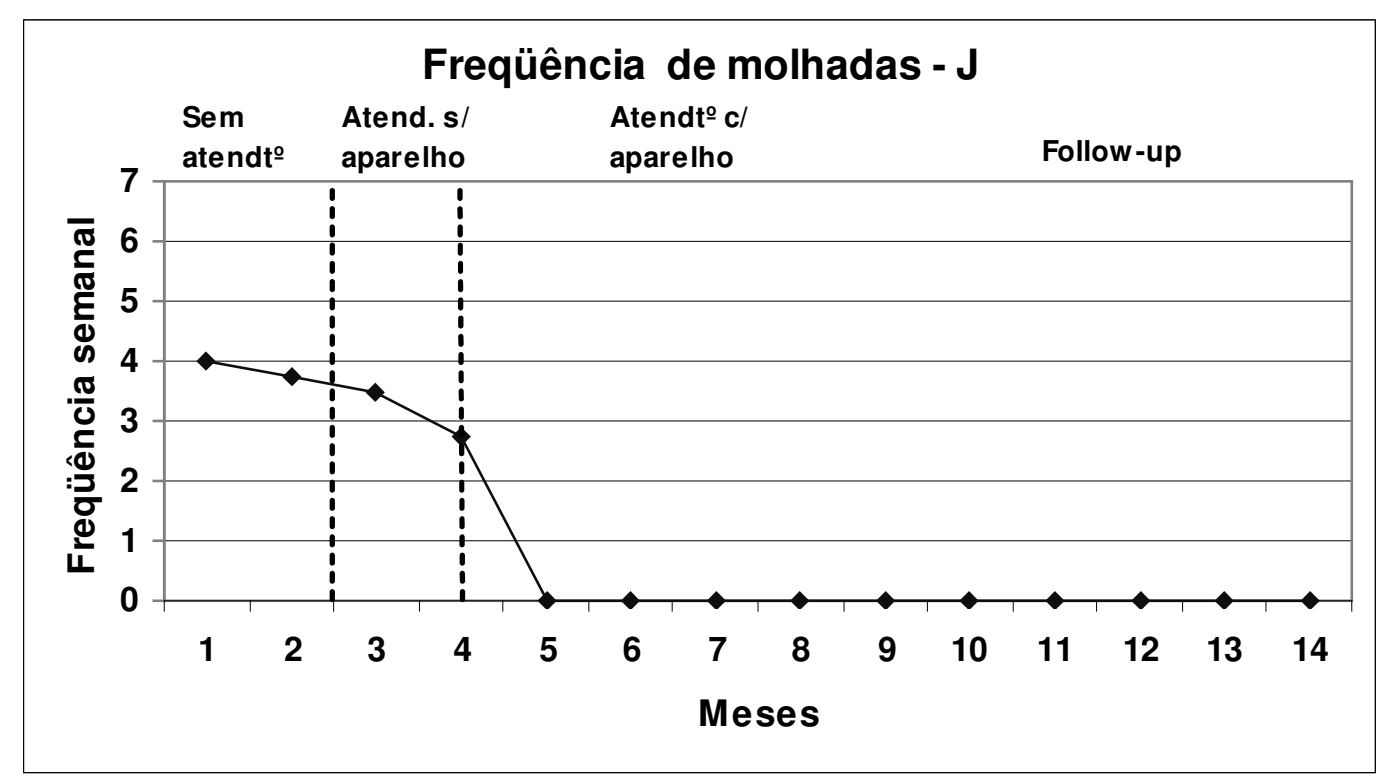

Na sexta sessão de atendimento foi introduzido o aparelho de alarme de urina, seguindo-se as instruções já mencionadas anteriormente. Os episódios de molhadas continuaram por mais três semanas, ao final das quais desapareceram. $\mathrm{O}$ atendimento continuou até a $29^{\mathrm{a}}$ semana, totalizando, portanto, 20 semanas sem um episódio sequer.

Foi realizada superaprendizagem nas semanas finais, e a resposta foi muito favorável, J. manteve o controle sem nenhum episódio enurético desde então.

Ao final do atendimento, além da extinção do comportamento enurético, verificou-se também mais atenção aos cuidados pessoais por parte de J. Ela também passou a dedicar-se a atividades físicas, freqüentando regularmente aulas esportivas e academia de ginástica. J. e os próprios pais relataram melhoria nas interações com as irmãs e entre eles. Sinalizaram para a mudança do humor que ela apresentava; antes quase sempre deprimido e irritadiço. Ela mesma se percebia como "alguém muito mais agradável" (Sic).

Através de contato telefônico pode-se verificar que os resultados do atendimento eram mantidos no seguimento de 6 meses.

\section{CONSIDERAÇÕES FINAIS}

Os resultados indicam que a intervenção cognitivo comportamental com uso de aparelho de alarme de urina foi eficaz em ambos os casos. Um fator importante para tal resultado foi a colaboração dos pais, confirmando Silvares (1995). Em todo o processo demonstraram-se colaboradores, tanto na freqüência aos encontros semanais quanto nas mudanças na interação familiar.

Ao final do atendimento, através de relatos espontâneos dos participantes e de seus pais, verificaram-se efeitos positivos além da superação da queixa inicial. Em ambos os casos foram relatadas melhoras nas interações no ambiente familiar, propiciando melhor adaptação e relações mais saudáveis. No primeiro caso, que manifestava maior isolamento e grande timidez, foi marcante a mudança no ambiente familiar como também fora dele. No segundo caso, foi mais visível a mudança na autoimagem e nas interações com familiares.

\section{REFERÊNCIAS}

Aberastury, A. \& Knobel, M. (1992). Adolescência normal. Porto Alegre: Artes Médicas.

Achenbach, T. M. (1991). Integrative guide for the 1991 CBCL/ 4-18, YSR, and TRF Profiles. Burlington: University of Vermont.

American Psychiatric Association. (1994). Diagnostic and statistical manual of mental disorders (4. ed.). Washington, DC: American Psychiatric Association.

Bethencourt, P. J. M.; Garcia, M. P.; Ramos, P.C.; Diaz, C.F. \& Fernandez, V. A. (1997). Análisis y Modificación de Conducta, 23 (87), 39-57.

Blackwell, C. (1989). A Guide to Enuresis: A guide to a treatment of enuresis for professionals. Bristol: Enuresis Resource and Information Center.

Bordin, I. A. S.; Mart, J. J. \& Caeiro, M. F. (1995). Validação da versão brasileira do 'Child Behavior Checklist' (CBCL) (Inventário de Comportamentos da Infância e Adolescência): dados preliminares. Revista $A B P-A P A L, 17$ (2): 55-56.

Butler, R. J. (1987). Nocturnal Enuresis: Psychological Perspectives. Bristol: Wright.

Doleys, D. M. (1977). Behavioral treatments for nocturnal enuresis in children: a review of the recent literature. Psychological Bulletin, 84 (1), 30-54.

Gontard, A. \& Lehmkuhl, G. (1997). Nocturnal enuresis: a review of genetic, pathophysiologic, and psychiatric associations. Praxis der Kinderpsychologie und Kinderpsychiatrie, 46 (10), 709-726.

Houts, A. C. (1991). Nocturnal enuresis as a biobehavioral problem. Behavior Therapy, 22, 33-151. 
Houts, A. C., Berman, J. S. \& Abramson, H. (1994). Effectiveness of psychological and pharmacological treatments for nocturnal enuresis. Journal of Consulting and clinical Psychology, 62 (4), 737-745.

Kelleher, R. E. (1997). Daytime and nighttime wetting in children: a review of management. Journal of the Society of Pediatric Nurses, 2 (2), 73-82.

Marinho, M. L. (1999). Orientação de pais em grupo: intervenção sobre diferentes queixas comportamentais infantis. Tese de Doutorado apresentada ao Programa de Pós-Graduação do Instituto de Psicologia da Universidade de São Paulo.

Mars, R. C. D. (1999). Treating Primary Nocturnal Enuresis: The Counselor's Role. Applied and Preventative Psychology, 1, 15-22.

Mellon, M. W. \& Houts, A. C. (1995). Eliminations Disorders. Em M. Cimmerman \& M. Hersen (Orgs.), Handbook of Child Behavior Therapy in the Psychiatric Setting (pp. 341-346). New York: The Guilford Press.

Moffat, M. E. K. (1997). Nocturnal enuresis: a review of the efficacy of treatments and practical advice for clinicians. Journal of Developmental and Behavioral Pedia-trics, 18 (1), 49-56.

Morgan, R. T. T. \& Young, G. C. (1975). Parental attitudes and the conditioning treatment of childhood enuresis. Behavior Research and Therapy, 13, 197-199.
Oliveira, D. S. (1999). O uso do aparelho de alarme no tratamento comportamental da enurese infantil noturna. Dissertação de Mestrado apresentada ao Programa de Pós-Graduação do Instituto de Psicologia da Universidade de São Paulo.

Silvares, E. F. M. S. (1996). Enurese noturna: um tratamento alternativo. Pediatria Moderna, 22, 662-667.

Silvares, E. F. M. S. (2001). Avaliação da competência social e dos distúrbios de comportamento, através do CBCL, em crianças brasileiras encaminhadas para avaliação psicológica em clínicas-escola de Psicologia, situadas em diferentes regiões do país. Projeto Temático submetido à apreciação da FAPESP.

Silvares, E. F. M. S. (1995). O modelo triádico no contexto da terapia comportamental com famílias. Psicologia: Ciência e Profissão, 11 (3), 235-241.

Wille, S. (1986.) Comparison of desmopressin and enuresis alarm for nocturnal enuresis. Archives of Disease in Childhood, 61 (7), 111-117.

Recebido: 23.04 .2003

Revisado:20.07.2003

Aceito:30.07.2003

\section{Sobre os autores}

Noel José Dias da Costa: Psicólogo - aluno de pós-graduação do IPUSP, nível mestrado. Endereço para correspondência: Rua Candal, $\mathrm{n}^{\circ} 1$, apt ${ }^{\circ} 81$, jd. Amália, CEP 05890-030 - São Paulo - SP; e-mail: noelbhmg@ yahoo.com.br.

Edwiges Ferreira de Mattos Silvares: Coordenadora do Projeto Enurese e Prof ${ }^{a}$ Titular do Instituto de Psicologia da Universidade de São Paulo - USP - bolsista CNPq. 

